\title{
Obesity, Outcomes and Quality of Care: BMI Increases the Risk of Wound-Related Complications in Colon Cancer Surgery
}

\author{
Ramzi Amri, MSc, Liliana G. Bordeianou, MD, MPH, Patricia Sylla, MD, and David L. Berger, \\ MD \\ Harvard Medical School and Massachusetts General Hospital, Boston, MA, United States
}

\begin{abstract}
Background-Obese patients may face higher complication rates during surgical treatment of colon cancer. This paper aims to measure this effect in a high volume tertiary care center.

Methods-All colon cancer patients treated surgically at our center from 2004 through 2011 were reviewed. Multivariate regression assessed relationships of complications and stay outcomes with BMI controlled for age, gender, comorbidity score, surgical approach and history of smoking.

Results-In 1048 included patients, BMI was a predictor of several complications in both laparoscopic and open procedures. For every increase of BMI by one WHO category, the odds ratio $(\mathrm{OR})$ was $1.61(\mathrm{p}<0.001)$ for wound infection and $\mathrm{OR}=1.54$ for slow healing $(\mathrm{p}<0.001)$. Additionally, right colectomies had an $\mathrm{OR}=3.23(\mathrm{p}=0.017)$ for wound dehiscence. No further associations with BMI were found.
\end{abstract}

Conclusions-BMI was incrementally associated with wound-related complications, illustrating how the proliferation of obesity relates to a growing risk of surgical complications. As the surgical community strives to improve quality of care, patient controllable factors will play an increasingly important role in cost containment and quality improvement.

\section{Keywords}

Colon cancer; obesity; body mass index; postoperative complications; perioperative outcomes

\section{Introduction}

Obesity is still on the rise in the Western world and continues to be a growing challenge for the surgical community. In the United States, the proportion of obese adults has steadily increased over the last 50 years. In 1962, 13.4\% of adults were classified as obese ${ }^{1}$ and now

\footnotetext{
(C) 2013 Excerpta Medica, Inc. All rights reserved.

Corresponding author: David L. Berger, M.D. Massachusetts General Hospital Division of General Surgery \& Gastrointestinal Surgery 15 Parkman Street 02114 Boston, MA Telephone: +1-617-724-6980 Fax: +1-617-724-0067 berger.david@mgh.harvard.edu. Publisher's Disclaimer: This is a PDF file of an unedited manuscript that has been accepted for publication. As a service to our customers we are providing this early version of the manuscript. The manuscript will undergo copyediting, typesetting, and review of the resulting proof before it is published in its final citable form. Please note that during the production process errors may be discovered which could affect the content, and all legal disclaimers that apply to the journal pertain.

Author Contributions: Dr. Berger had full access to all the data in the study and takes responsibility for the integrity of the data and the accuracy of the data analysis. Study concept and design: Amri and Berger. Acquisition of data: Amri and Berger. Analysis and interpretation of data: Amri and Berger. Drafting of the manuscript: Amri and Berger. Critical revision of the manuscript for important intellectual content: Amri, Bordeianou, Sylla and Berger. Statistical analysis: Amri. Obtained funding: Amri and Berger. Administrative, technical, and material support: Amri, Bordeianou, Sylla and Berger. Study supervision: Berger.
}

Financial Disclosure: None. 
$35.7 \%$ of adults in the US are obese according to the latest data from the Centers for Disease Control. ${ }^{2}$ Meanwhile, hospitals and surgeons are striving to improve their outcomes and reduce their complication rates. The Surgical Care Improvement Project (SCIP) measures and guidelines, meant to improve the quality of care ${ }^{3}$ as well as the National Surgical Quality Improvement Program (NSQIP) surveying are now commonplace. ${ }^{4,5}$

Hospitals and surgeons are judged on their performance. However, obesity, which is a patient controlled risk factor, is beyond the control of the medical community but plays an important role in surgical outcomes. Obesity is suspected to increase resection difficulty ${ }^{6}$ and to be predictive of a complicated postoperative course, ${ }^{7,8}$ although this premise has also been disputed. ${ }^{9-11}$

Colon cancer is affected by obesity as an etiological risk factor, ${ }^{12-14}$ but it may also be a potential complicating factor during surgical treatment. The higher prevalence of obesity, combined with the abdominal location and the relatively advanced median age of affected patients ${ }^{15}$ may be a triad that exacerbates the risk of obesity-related complications during operative management of colon cancer.

Over 100.000 new cases of colon cancer are diagnosed each year in the US ${ }^{15}$ and surgical resection is indicated for the vast majority of these. Meanwhile, obesity rates are reaching new heights, yet current literature fails to provide unequivocal, reliable evidence on links between obesity and colon cancer surgery complications. Even scarcer is evidence concerning these potential links in centers that have been compliant to SCIP guidelines and who are NSQIP implementers.

Body Mass Index (BMI) is a widely used numeric expression of body habitus by using patient weight in relationship to height squared (unit $\mathrm{kg} / \mathrm{m}^{2}$ ). It is closely related to percentage body fat and total body fat ${ }^{16}$ and is the measure used to define a threshold value for obesity. This study therefore measures the effect of BMI on operative outcomes and the risk of postoperative complications in a center that has been among the early adopters of NSQIP in the private sector. ${ }^{17}$

\section{Methods}

\section{Patients}

All patients surgically treated for colonic adenocarcinoma at Massachusetts General Hospital from 2004 through 2011 were included. Data on all cases was gathered from medical records and hospital data repositories as defined by an institutional review boardapproved protocol. Patients without known BMI were the only ones to be excluded from further analysis.

Perioperative BMI was determined using several sources, including the operative anesthesia record, preadmission history and physical, preoperative anesthesia examination and physical examination by operating surgeon. In case of discrepancies, patient history and outside records were also reviewed to identify the most accurate measurement.

Links were assessed between BMI and outcomes including duration of surgery, conversion rate, duration of stay and postoperative complications. Most complications were actively reported due to our center's enrollment to ACS NSQIP throughout the time span of this research. Some complications were further specified in our database for the sake of this research according to their clinical magnitude: Wound infection was any culture-ascertained infection or infectious redness or discharge located at the operative wound severe enough to necessitate targeted attention, including antibiotic treatment. Slow healing included any 
operative wound that was the independent cause of a longer stay or led to targeted and unplanned clinical attention, not limited to infectious origins.

Bowel motility delay was any return of bowel function that took substantially longer than initially expected and necessitated an unplanned intervention, like the (re)placement of a nasogastric tube or initiation of parenteral nutrition. Fascial dehiscence, bowel obstructions, anastomotic leaks, bowel perforations and colitis were all empirically established, usually ascertained through imaging or appropriate lab work.

BMI was categorized following the classification defined by the WHO in $2000^{18}$ : these groups were underweight (BMI below 18.5), normal (BMI 18.5-24.9), preobese (25-29.9) and obese grades I (30 - 34.99), II (35-39.99) and III (above 40). Following direct association measures, BMI was also controlled for possible confounders, including baseline characteristics that could influence its link with outcomes. These were: age, race, gender, comorbidity scores and smoking status. Baseline characteristics found to significantly influence BMI were considered in multivariate models. For complications found to be significantly associated with BMI, a further detailed breakdown was made based on resection region (right colectomies, left colectomies, or sigmoid/low anterior), admission type (urgent vs. elective), and surgical approach (open vs. laparoscopic).

\section{Statistical analysis}

Statistical significance was defined as a $p$-value of $\mathrm{p}=0.05$ or lower. Statistical analysis was performed using SPSS software (IBM Corp. Released 2011. IBM SPSS Statistics for Windows, Version 20.0. Armonk, NY: IBM Corp.). Bivariate Pearson correlation was measured between BMI and baseline characteristics. Univariate analysis assessed the statistical significance of differences between groups using the Chi-squared $\left(X^{2}\right)$ test for nominal variables and an analysis of variance (ANOVA) for continuous numbers. In multivariate analysis, binary logistic regression was used for dichotomous outcomes, while linear regression was used for continuous outcomes. The most appropriate multivariate model in terms of included covariates was selected based on model fit $\left(\mathrm{R}^{2}\right)$.

\section{Results}

Of the 1071 patients operated on for colon cancer in the defined time interval, $1048 \mathrm{had}$ reliable information to determine BMI. The 23 excluded patients lacked height determination when it was deemed impractical or irrelevant to the patient's care at admission (e.g. severe scoliosis, wheelchair bound, emergency protocol etc.). These patients did not differ substantially from the included patients in any aspect.

\section{Baseline characteristics}

The baseline characteristics and their correlations with BMI are shown in Table 1. Patients' age was inversely correlated with BMI $(r=-.161 \mathrm{p}<0.001)$. There was no association with race, while there was a positive correlation with male gender $(r=0.118 ; \mathrm{p}<0.001)$. The Charlson Comorbidity Score was not associated with BMI, while ASA score did weakly but significantly correlate $(r=.080 ; \mathrm{p}=0.01)$. BMI was also inversely correlated with a past history of smoking ( $r=-.092 ; \mathrm{p}=0.003$ ) but this was not found in current smoking. Lastly, there was no association between surgical approach and weight $(\mathrm{p}=0.088)$.

\section{Complications}

Overall complication rates are shown in table 2: wound infection, slow wound healing and fascial dehiscence were associated with BMI (all $\mathrm{p}<0.001$ ). Other complications, conversion risk, as well as 30-day reoperation, readmission and death rates were not related to BMI. 
Logistic regression was used to calculate the overall odds ratios (OR) for the measured complications between successive BMI intervals. These are shown in a Forest plot in Figure 1. For every increase in BMI category, the odds of having a wound infection within 30 days postoperatively increased by an OR of $1.61(\mathrm{p}<0.001)$, slow healing had an OR of 1.54 $(\mathrm{p}<0.001)$, and fascial dehiscence an OR of $2.87(\mathrm{p}=0.001)$.

These findings were subsequently explored further by reviewing the associations for major resection regions and for emergency and elective surgeries. Table 3 displays these results. Left-sided colectomies were at particular risk of wound infections ( $\mathrm{OR}=2.15, \mathrm{p}<0.001)$ and slow healing $(\mathrm{OR}=2.16, \mathrm{p}<0.001)$, whereas fascial dehiscence appeared to be strongly associated with right-sided colectomies $(\mathrm{OR}=3.23, \mathrm{p}=0.017)$. Outcomes were similar in the overall population and the elective-only population. Urgent resections were not significantly associated with the complications but trends appeared to be comparable, the lack of statistical significance may be the effect of the small sample size, as they accounted for only about $9 \%$ of our population.

\section{Multivariate analysis}

The three complications found to be significantly related to BMI were included in binary multivariate logistic regression accounting for covariates and reviewing the OR for unit of BMI as well as for category increases of BMI. These outcomes are shown in Table 4: variations in OR for specific approaches were largely within the immediate range of the original values. The only clearly added risk factor in open procedures being an increase in OR for fascial dehiscence ( $\mathrm{p}=0.009$ ). In laparoscopic procedures, the OR for wound infection was surprisingly slightly higher than they were in open procedures. Slow wound healing was borderline significant ( $\mathrm{p}=0.056$ ) for continuously approached BMI while BMI intervals still were significantly associated $(\mathrm{p}=0.043)$. Fascial dehiscence after laparoscopic procedures was not associated with BMI divided over categories $(\mathrm{p}=0.99)$ while still having a relative increase in odds of $\mathrm{OR}=1.344(\mathrm{p}=0.045)$ for every increase of BMI by one unit. All other complications were non-significant regardless of the used set of covariates and therefore omitted from Table 4 for legibility purposes.

\section{Discussion}

The surgical community strives to improve patient care by implementing guidelines that ensure risks and preventable complications are identified, kept at a minimum and avoided in a systematic way. Over the last two decades, a fast-growing trend of standardization and benchmarking of quality of care led to the implementation of increasingly detailed and demanding guidelines in the United States. After the successive introductions of (Veterans Administration) NSQIP in $1994^{19}$ and ACS NSQIP in 2004, 5 as well as SIP in 2002 and SCIP in $2006^{3}$, these universal standards have provided very successful tools to track and tackle many perioperative issues.

It is, however, important to keep in mind that many factors leading to complications are often simply out of the medical community's immediate control. Obesity is one of these patient-controlled factors, and it can be a significant challenge in virtually any medical intervention. Although the link between obesity and difficulties in abdominal surgery is intuitive, both its effects and their magnitude are disputed. Reports on this subject have been conflicting and it remains to be conclusively established what the risks are in more specific cases. This paper therefore aimed to give an answer on the role of obesity in the surgical treatment of colon cancer by establishing the relationship between BMI and postoperative complications and outcomes. 
The first step was to identify any factors that could influence these relationships. All relevant baseline characteristics were therefore examined. We noted that our BMI distribution was below the national average, which is a finding that matches the differences in state averages as reported by the CDC. ${ }^{20}$ Since we use methods that are not influenced by the distribution of obesity in the population, this should not be an issue in the interpretation of our findings. We have also noted that BMI had an inverse correlation with age. Even though this was explainable through the physiology of aging, ${ }^{21}$ older age is also possibly related to higher risks of complications, so it was important to verify for any potential confounding effect in multivariate analysis. Differences in BMI between genders were statistically significant and match reports that describe a higher median BMI in men in the United States. ${ }^{2}$ It was therefore reasonable to account for this difference in multivariate models as well. ASA score differences were likely an expression of the relationship between body habitus and several comorbid diseases that could raise this score. Lastly, the negative correlation between BMI and former smoking could be explained by coinciding changes in lifestyle, which led both to weight loss and the decision to stop smoking. The subsequently confirmed relationship between former smoking in multivariate models as a predictor of impaired wound healing issues associated with BMI is quite possibly an expression of the known accelerating effect of long-term cigarette smoking on skin aging, ${ }^{22}$ which in turn contributes to the impaired healing.

Our analysis demonstrated that increases in BMI do not correlate with many complications and do not significantly contribute to an increase in length of stay, surgery duration, conversion, readmission, reoperation or death rates. They are, however, a clear risk factor for several wound-related complications. Regional breakdown of procedures demonstrated that left-sided resections were at particular risk of wound infections and slow healing, and that fascial dehiscence was strongly related to right-sided resections, although there is no apparent explanation for these regional differences. In addition, our multivariate models show that the increases in relative odds of complications were independent of age and comorbidity. Findings were similar after urgent procedures were removed from the sample, and regardless of surgical technique used. The findings for laparoscopic resections did, however, have larger p-values. This is likely to be the result of a smaller sample size, rather than the expression of a weaker association between BMI and the aforementioned complications in laparoscopic cases.

This illustrates a limitation of our study: even with a set of over 1000 patients, we still had inherent difficulties with identifying the analyzed trends in certain subsets, such as certain approaches, procedures, or urgent cases. This also partially impaired the use of multivariate models on those smaller groups. This same issue may make it more difficult to find statistically significant findings for complications that did not occur frequently. However, as illustrated by the fascial dehiscence example, which was highly significantly linked with BMI with only seven overall occurrences, this does not need to be a limitation except for the inherent difficulty of performing subset analyses for those low-incidence findings.

The findings of this paper are an addition to a widely addressed topic. Many papers have described related outcomes, with very different results: some have used national (VA) NSQIP data to identify risk factors for postoperative morbidity, but did not identify BMI as a risk factor. ${ }^{23} \mathrm{~A}$ previous study performed at our center compared only obese with nonobese patients with colonic adenocarcinoma and was not able to find the association using a smaller sample size. ${ }^{11}$ Other studies identified links between BMI and overall complications in surgical colon cancer patients using the NSQIP database, but only for those over $65^{24}$ or identified a higher risk of wound infection and dehiscence, but only for morbidly obese patients. ${ }^{25}$ 
Our extensive analysis of a large consecutive set of colon cancer patients also enabled us to demonstrate that the relative odds of wound-related complications tended to incrementally increase throughout weight categories. This also means that preobese people are at an increased risk compared to people with a healthy BMI. There is a significant potential for risk reduction to be found in every category above ideal weight. It would have been very interesting to assess if the underweight group was also at higher risk of any of the indexed complications. However, our sample was too small to produce meaningful results. This may be an interesting topic for further research.

Our findings are especially interesting considering that both the SCIP and NSQIP efforts put a strong emphasis on surgical site infections and our center has been among the early implementers of these guidelines with the aim to improve surgical outcomes service-wide. ${ }^{17}$ This shows that even after significant and successful efforts to achieve reductions in complication rates, factors outside the grasp of the surgical community can influence these outcomes. Lastly, even though obesity may be outside the realm of the surgeon or the hospital, it should not be ignored and presents significant problems when trying to improve morbidity or mortality rates.

\section{Acknowledgments}

This work was conducted with support from Harvard Catalyst | The Harvard Clinical and Translational Science Center (National Center for Research Resources and the National Center for Advancing Translational Sciences, National Institutes of Health Award 8UL1TR000170-05 and financial contributions from Harvard University and its affiliated academic health care centers). The content is solely the responsibility of the authors and does not necessarily represent the official views of Harvard Catalyst, Harvard University and its affiliated academic health care centers, or the National Institutes of Health.)

This work was also supported in part by the Dutch Cancer Society, the Dutch Digestive Society, the Amsterdam University Funds, the Royal Netherlands Academy of Arts and Sciences and the Fulbright Foundation.

\section{References}

1. United States Department of Health and Human Services; National Center for Health Statistics. National Health Examination Survey, Cycle I, 1959-1962: Body Measurements. 1989 doi:10.3886/ ICPSR09203.v1.

2. Flegal KM, Carroll MD, Kit BK, Ogden CL. Prevalence of obesity and trends in the distribution of body mass index among US adults, 1999-2010. JAMA. 2012; 307(5):491-497. doi:10.1001/jama. 2012.39. [PubMed: 22253363]

3. Bratzler DW, Hunt DR. The surgical infection prevention and surgical care improvement projects: national initiatives to improve outcomes for patients having surgery. Clin. Infect. Dis. 2006; 43(3): 322-330. doi:10.1086/505220. [PubMed: 16804848]

4. Rosenberger LH, Politano AD, Sawyer RG. The surgical care improvement project and prevention of post-operative infection, including surgical site infection. Surg Infect (Larchmt). 2011; 12(3): 163-168. doi:10.1089/sur.2010.083. [PubMed: 21767148]

5. Hall BL, Hamilton BH, Richards K, Bilimoria KY, Cohen ME, Ko CY. Does surgical quality improve in the American College of Surgeons National Surgical Quality Improvement Program: an evaluation of all participating hospitals. Ann. Surg. 2009; 250(3):363-376. doi:10.1097/SLA. 0b013e3181b4148f. [PubMed: 19644350]

6. Khoury W, Stocchi L, Geisler D. Outcomes after laparoscopic intestinal resection in obese versus non-obese patients. Br J Surg. 2011; 98(2):293-298. doi:10.1002/bjs.7313. [PubMed: 21110332]

7. Benoist S, Panis Y, Alves A, Valleur P. Impact of obesity on surgical outcomes after colorectal resection. Am. J. Surg. 2000; 179(4):275-281. [PubMed: 10875985]

8. Bamgbade OA, Rutter TW, Nafiu OO, Dorje P. Postoperative complications in obese and nonobese patients. World J Surg. 2007; 31(3):556-60. - discussion 561. doi:10.1007/s00268-006-0305-0.

[PubMed: 16957821] 
9. Leroy J, Ananian P, Rubino F, Claudon B, Mutter D, Marescaux J. The impact of obesity on technical feasibility and postoperative outcomes of laparoscopic left colectomy. Ann. Surg. 2005; 241(1):69-76. [PubMed: 15621993]

10. Dindo D, Muller MK, Weber M, Clavien P-A. Obesity in general elective surgery. Lancet. 2003; 361(9374):2032-2035. doi:10.1016/S0140-6736(03)13640-9. [PubMed: 12814714]

11. Bamboat ZM, Kinnier C, Dursun A, et al. Short-term outcomes in obese patients after colectomy for adenocarcinoma at a bariatric center. J. Gastrointest. Surg. 2012; 16(10):1923-1928. doi: 10.1007/s11605-012-1978-3. [PubMed: 22847573]

12. Calle EE, Rodriguez C, Walker-Thurmond K, Thun MJ. Overweight, obesity, and mortality from cancer in a prospectively studied cohort of U.S. adults. N. Engl. J. Med. 2003; 348(17):16251638. doi:10.1056/NEJMoa021423. [PubMed: 12711737]

13. American Institute for Cancer Research. Food, Nutrition, Physical Activity, and the Prevention of Cancer. Amer Inst for Cancer Research; 2007.

14. Kushi LHL, Byers TT, Doyle CC, et al. American Cancer Society Guidelines on Nutrition and Physical Activity for cancer prevention: reducing the risk of cancer with healthy food choices and physical activity. CA Cancer J Clin. 2006; 56(5):254-254. doi:10.3322/canjclin.56.5.254. [PubMed: 17005596]

15. Siegel R, Naishadham D, Jemal A. Cancer statistics, 2012. CA Cancer J Clin. 2012; 62(1):10-29. doi:10.3322/caac.20138. [PubMed: 22237781]

16. Gray DS, Fujioka K. Use of relative weight and Body Mass Index for the determination of adiposity. J Clin Epidemiol. 1991; 44(6):545-550. [PubMed: 2037859]

17. Rowell KS, Turrentine FE, Hutter MM, Khuri SF, Henderson WG. Use of national surgical quality improvement program data as a catalyst for quality improvement. J. Am. Coll. Surg. 2007; 204(6): 1293-1300. doi:10.1016/j.jamcollsurg.2007.03.024. [PubMed: 17544087]

18. World Health Organization. Obesity : preventing and managing the global epidemic : report of a WHO consultation. World Health Organization; Geneva: 2000.

19. Fink AS, Campbell DA, Mentzer RM, et al. The National Surgical Quality Improvement Program in non-veterans administration hospitals: initial demonstration of feasibility. Ann. Surg. 2002; 236(3):344-53. - discussion 353-4. doi:10.1097/01.SLA.0000027082.79556.55. [PubMed: 12192321]

20. Centers for Disease Control and Prevention (CDC). Behavioral Risk Factor Surveillance System Survey Data. U.S. Department of Health and Human Services, Centers for Disease Control and Prevention; Atlanta, Georgia: 2011.

21. Chapman IM. The anorexia of aging. Clin. Geriatr. Med. 2007; 23(4):735-56. - v. doi:10.1016/ j.cger.2007.06.001. [PubMed: 17923335]

22. Helfrich YR, Yu L, Ofori A, et al. Effect of smoking on aging of photoprotected skin: evidence gathered using a new photonumeric scale. Arch Dermatol. 2007; 143(3):397-402. doi:10.1001/ archderm.143.3.397. [PubMed: 17372106]

23. Longo WE, Virgo KS, Johnson FE, et al. Risk factors for morbidity and mortality after colectomy for colon cancer. Dis. Colon Rectum. 2000; 43(1):83-91. [PubMed: 10813129]

24. Kennedy GD, Rajamanickam V, O'connor ES, et al. Optimizing surgical care of colon cancer in the older adult population. Ann. Surg. 2011; 253(3):508-514. doi:10.1097/SLA.

0b013e3181f19518. [PubMed: 21169811]

25. Merkow RP, Bilimoria KY, McCarter MD, Bentrem DJ. Effect of body mass index on short-term outcomes after colectomy for cancer. J. Am. Coll. Surg. 2009; 208(1):53-61. doi:10.1016/ j.jamcollsurg.2008.08.032. [PubMed: 19228503] 


\section{Summary}

This paper evaluates the role of body habitus in complication rates and stay characteristics during the surgical treatment of colon cancer in a consecutive series of 1048 patients at a tertiary care center that was among the early adopters of NSQIP and SCIP guidelines. Higher BMI was associated with significantly higher rates of wound infections and slow wound healing. In right colectomies, higher BMI was also associated with higher odds of wound dehiscence. These findings underline how patient controllable factors will play an increasingly important role in cost containment and quality improvement. 


\begin{tabular}{lcc}
\multicolumn{1}{c}{ Complication } & OR & $95 \% C I$ \\
\hline ICU transfer & $1.16(0.88-1.55)$ \\
Anastomotic leak & $1.09(0.75-1.57)$ \\
GI bleed & $0.73(0.33-1.62)$ \\
Sepsis & $1.12(0.74-1.70)$ \\
Colitis & $0.91(0.53-1.54)$ \\
Bowel perforation & $0.61(0.21-1.79)$ \\
Bowel obstruction & $1.04(0.63-1.72)$ \\
Delayed bowel motility & $0.97(0.82-1.15)$ \\
30-day mortality & $0.91(0.57-1.46)$ \\
30-day readmission & $1.10(0.91-1.32)$ \\
30-day reoperation & $1.19(0.88-1.61)$ \\
Conversion & $1.10(0.85-1.42)$ \\
Fascial dehiscence & $2.87(1.29-3.93)$ \\
Slow wound healing & $1.55(1.31-1.83)$ \\
Wound infection & $1.61(1.34-1.93)$ \\
\hline
\end{tabular}

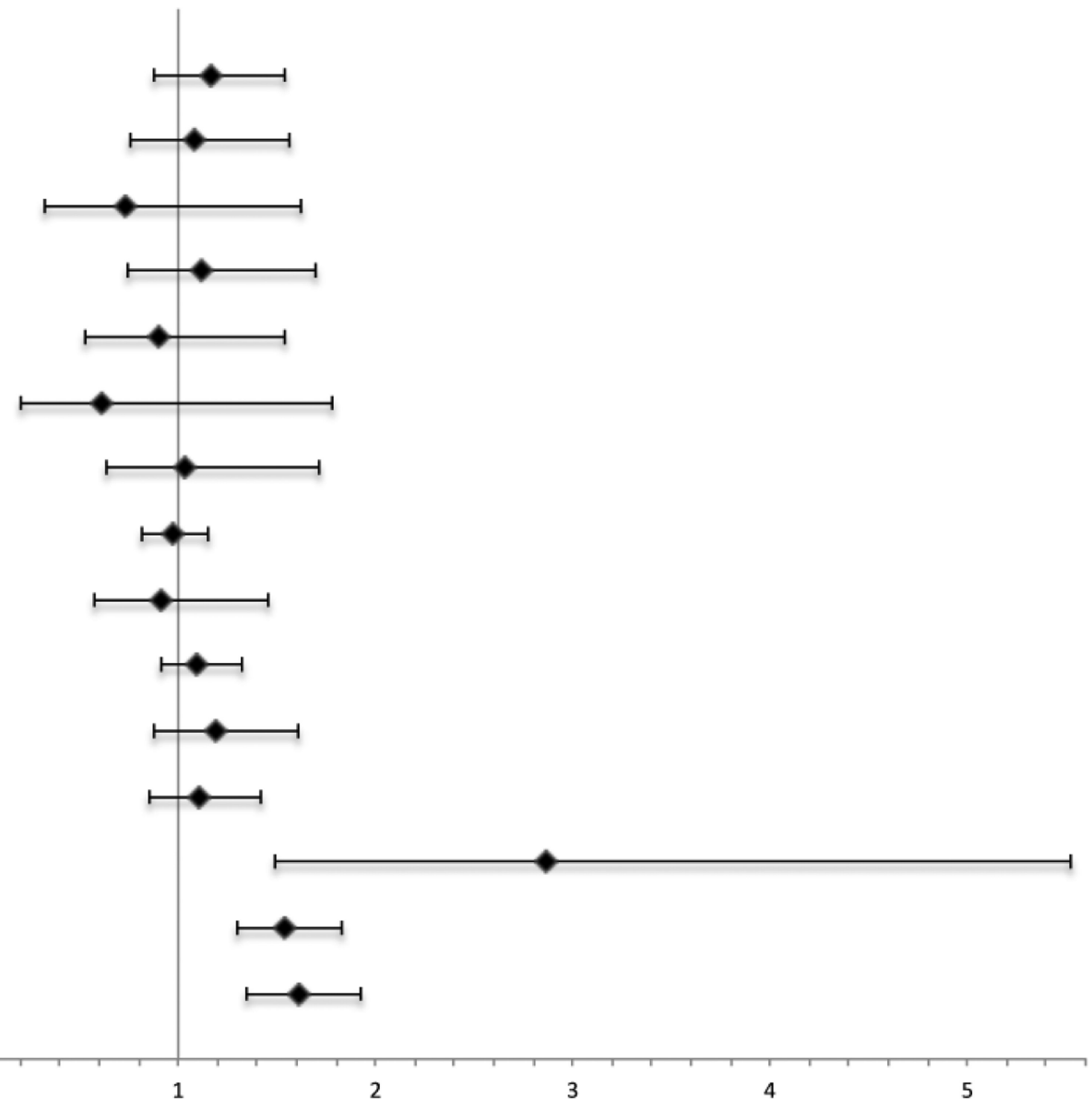

Figure 1.

Forest Plot displaying the odds ratio between two successive WHO BMI categories for all major abdominal complications in the general colon cancer population Error bars show 95\% Confidence interval. Complications with a 95\% CI that crosses the $y=1$ line have a non-significant odds ratio. 
Table 1

Baseline characteristics and their correlation with BMI

\begin{tabular}{|c|c|c|c|}
\hline Characteristics & Means & \multicolumn{2}{|c|}{ BMI correlation } \\
\hline BMI, $\mathrm{kg} / \mathrm{m}^{2}$ (range $\left.\pm \mathrm{SD}\right)$ & $27.6(14.7-59.5 \pm 6.35)$ & & \\
\hline Underweight $(\%<18.5)$ & 3.4 & & \\
\hline Healthy (\% 18.5-24.9) & 34.6 & & \\
\hline Preobese (\% 25.0-29.9) & 33.2 & & \\
\hline Class I obesity (\% 30-34.9) & 17.1 & & \\
\hline Class II obesity (\% 35-39.9) & 6.8 & & \\
\hline \multirow[t]{2}{*}{ Class III obesity $(\%>40)$} & \multicolumn{3}{|l|}{4.9} \\
\hline & \multicolumn{2}{|c|}{ Correlation } & $\mathbf{P}$ \\
\hline Age, y (range \pm SD) & $66.6(26-97 \pm 14)$ & -0.161 & $<.001$ \\
\hline Race (\% Caucasian) & 89.8 & NS & .376 \\
\hline Gender ( $\%$ male $)$ & 51.2 & 0.118 & $<.001$ \\
\hline ASA Score (range \pm SD) & $2.36(2-4 \pm 0.6)$ & 0.080 & .010 \\
\hline Charlson Score (range \pm SD) & $3.19(2-12 \pm 1.7)$ & NS & .77 \\
\hline Current smoking $(\%)$ & 12 & NS & .26 \\
\hline History of smoking (\%) & 40.7 & -0.092 & .003 \\
\hline Technique $(\%)$ & & NS & .088 \\
\hline Open & 69 & & \\
\hline Laparoscopic & 18.4 & & \\
\hline Lap. or hand assisted & 12.6 & & \\
\hline
\end{tabular}


Table 2

Complication rates per BMI category

\begin{tabular}{|c|c|c|c|c|c|c|c|}
\hline & \multicolumn{7}{|c|}{ BMI categories } \\
\hline & Underweight n=36 & Normal $n=363$ & Preobese $n=326$ & Obese I $n=179$ & Obese II n=71 & Obese III n=51 & $\mathbf{P}$ \\
\hline $\begin{array}{l}\text { Conversion, } n / n \\
\text { lap }(\%)\end{array}$ & $0 / 3(0)$ & $10 / 68(14.7)$ & $7 / 69(10.1)$ & $6 / 36(16.7)$ & $1 / 11(8.3)$ & $2 / 5(40)$ & .44 \\
\hline $\begin{array}{l}\text { Surgery } \\
\text { duration, } \mathrm{n}(\mathrm{SD})\end{array}$ & $107( \pm 58)$ & $136( \pm 86)$ & $142( \pm 85)$ & $140( \pm 78)$ & $129( \pm 58)$ & $151( \pm 77)$ & .22 \\
\hline $\begin{array}{l}\text { Wound } \\
\text { infection, } n(\%)\end{array}$ & $0(0)$ & $12(3.3)$ & $22(6.3)$ & $21(11.7)$ & $12(16.9)$ & $7(11.7)$ & $<.001$ \\
\hline $\begin{array}{l}\text { Slow wound } \\
\text { healing, } n(\%)\end{array}$ & $0(0)$ & $18(5)$ & $26(7.5)$ & $24(13.4)$ & $11(15.5)$ & $10(19.6)$ & $<.001$ \\
\hline $\begin{array}{l}\text { Fascial } \\
\text { dehiscence, } n \\
(\%)\end{array}$ & $0(0)$ & $1(0.3)$ & $1(0.3)$ & $2(1.1)$ & $0(0)$ & $3(5.9)$ & $<.001$ \\
\hline $\begin{array}{l}\text { Bowel motility } \\
\text { delay, } n(\%)\end{array}$ & $2(5.6)$ & $37(10.2)$ & $41(11.8)$ & $22(12.3)$ & $5(7)$ & $3(5.9)$ & .51 \\
\hline $\begin{array}{l}\text { Bowel } \\
\text { obstruction, } n \\
\text { (\%) }\end{array}$ & $0(0)$ & $4(1.1)$ & $3(0.9)$ & $3(1.7)$ & $1(1.4)$ & $0(0)$ & .87 \\
\hline $\begin{array}{l}\text { Bowel } \\
\text { perforation, } n \\
(\%)\end{array}$ & $0(0)$ & $2(0.6)$ & $2(0.6)$ & $0(0)$ & $0(0)$ & $0(0)$ & .86 \\
\hline Colitis, $n(\%)$ & $0(0)$ & $5(1.4)$ & $4(1.1)$ & $1(0.6)$ & $0(0)$ & $1(2)$ & .8 \\
\hline Sepsis, $n(\%)$ & $1(2.8)$ & $6(1.7)$ & $3(0.9)$ & $1(0.6)$ & $2(2.8)$ & $2(3.9)$ & .35 \\
\hline GI bleed, $n(\%)$ & $0(0)$ & $4(1.1)$ & $0(0)$ & $2(1.1)$ & $0(0)$ & $0(0)$ & .34 \\
\hline $\begin{array}{l}\text { Anastomotic } \\
\text { leak, } n(\%)\end{array}$ & $1(2.8)$ & $6(1.7)$ & $7(2)$ & $2(1.1)$ & $3(4.2)$ & $1(2)$ & .71 \\
\hline $\begin{array}{l}\text { Stay duration, } \\
\text { days (SD) }\end{array}$ & $6.33( \pm 4.9)$ & $6.45( \pm 5.3)$ & $6.58( \pm 5.5)$ & $5.65( \pm 4.5)$ & $5.92( \pm 4.1)$ & $9.9( \pm 18.2)$ & .2 \\
\hline $\begin{array}{l}\text { In-stay death, } n \\
(\%)\end{array}$ & $1(2.8)$ & $5(1.4)$ & $2(0.6)$ & $1(0.6)$ & $1(1.4)$ & $2(3.9)$ & .3 \\
\hline $\begin{array}{l}\text { 30-day } \\
\text { reoperation, } n \\
(\%)\end{array}$ & $1(2.8)$ & $7(1.9)$ & $9(2.6)$ & $7(3.9)$ & $2(2.8)$ & $2(3.9)$ & .83 \\
\hline $\begin{array}{l}\text { 30-day } \\
\text { readmission, } n \\
\text { (\%) }\end{array}$ & $2(5.6)$ & $28(7.7)$ & $27(7.8)$ & $12(6.7)$ & $6(8.5)$ & $7(13.7)$ & .69 \\
\hline
\end{tabular}


Table 4

Multivariate models, elective cases only

\begin{tabular}{|c|c|c|c|c|}
\hline \multirow[b]{2}{*}{ Complication } & \multicolumn{2}{|c|}{ BMI categories } & \multicolumn{2}{|c|}{ BMI continuous } \\
\hline & $\mathbf{P}$ & OR & $\mathbf{P}$ & OR \\
\hline Wound infection ${ }^{\dagger}$ & $<.001$ & 1.60 & $<.001$ & 1.09 \\
\hline Open only $y^{\dagger} \S$ & $<.001$ & 1.57 & $<.001$ & 1.09 \\
\hline Laparoscopic only & .029 & 1.87 & .025 & 1.13 \\
\hline Slow wound healing $\S$ & $<.001$ & 1.53 & $<.001$ & 1.08 \\
\hline Open only ${ }^{\dagger}, \S$ & $<.001$ & 1.54 & $<.001$ & 1.08 \\
\hline Laparoscopic only ${ }^{*}$ & .043 & 1.71 & .056 & 1.10 \\
\hline Fascial Dehiscence & .001 & 2.26 & .001 & 1.14 \\
\hline Open only & .009 & 3.00 & .001 & 1.19 \\
\hline Laparoscopic only & .99 & NS & .045 & 1.34 \\
\hline
\end{tabular}

Rows show the odds ratio for the listed complication for every single upward step in BMI category (left) or increase of $1 \mathrm{~kg} / \mathrm{m}^{2}$ in BMI (right). Outcomes for are corrected for:

$\ddagger$ ASA score

age

$\dagger$ gender

$\S_{\text {history of smoking }}$ 